\title{
Tick-borne encephalitis virus (TBEV) - findings on cross reactivity and longevity of TBEV antibodies in animal sera
}

\author{
Christine Klaus $^{1 *+}$, Ute Ziegler ${ }^{2 \dagger}$, Donata Kalthoff ${ }^{3 \dagger}$, Bernd Hoffmann ${ }^{3+}$ and Martin Beer ${ }^{3+}$
}

\begin{abstract}
Background: By using animal sera as sentinels, natural TBEV foci could be identified and further analyses including investigations of ticks could be initiated. However, antibody response against TBEV-related flaviviruses might adversely affect the readout of such a monitoring. Therefore, the cross-reactivity of the applied TBEV serology test systems - enzyme linked immunosorbent assay (ELISA) and virus neutralization test (VNT) - as well as the longevity of TBEV antibody titres in sheep and goats were investigated in this study.
\end{abstract}

Results: Cross-reactivity of the TBEV antibody test systems with defined antibody-positive samples against selected members of the Flaviviridae family (e.g. Louping ill virus, West Nile virus) was observed for Louping-ill-positive sera only. In contrast, the commercial West Nile virus (WNV) competitive ELISA showed a high level of cross-reactivity with TBEV-specific positive sera.

To assess the longevity of TBEV antibody titres, sera from two sheep and two goats, which had been immunized four times with a commercially available TBEV vaccine, were tested routinely over 28 months. In three of the four animals, TBEV-specific antibody titres could be detected over the whole test period.

In addition, sera from the years 2010 and 2011 were collected in flocks in different villages of Baden-Württemberg and Thuringia to allow re-examination two to four years after the initial analysis. Interestingly, in most cases the results of the former investigations were confirmed, which may be caused by steadily existing natural TBEV foci.

Conclusion: Cross-reactivity must be taken into consideration, particularly for TBEV serology in regions with a prevalence of Louping ill virus and for serological testing of WNV by cross-reactive ELISAs. Furthermore, over-interpretation of single TBEV-positive serological results should be avoided, especially in areas without a TBEV history.

Keywords: Tick borne encephalitis, Animal sera, Virus neutralization test, ELISA, Cross-reactivity, Flaviviridae

\section{Background}

Tick-borne encephalitis (TBE) is the most important viral tick-borne zoonosis in Europe [1]. TBE virus (TBEV) circulates between ticks and hosts in geographically strictly limited natural foci, which can range in size from large to very small. However, the reason for the patchwork-like spread of TBEV is unclear [2-4]. TBEV prevalence in ticks in these natural foci is very low [5-7], and detection of a natural TBEV focus by collecting and testing ticks is very expensive

\footnotetext{
*Correspondence: DrChristineKlaus@gmail.com

${ }^{\dagger}$ Equal contributors

${ }^{1}$ Institute of Bacterial Infections and Zoonoses, Friedrich-Loeffler-Institut,

Naumburger Str. 96a, D-07743 Jena, Germany

Full list of author information is available at the end of the article
}

and time-consuming [8]. Against this background, assessment of the TBEV sero-prevalence in free-ranging animals provides a suitable and valuable additional source of information about TBEV foci in their smaller or larger patchy pattern [9-11].

In general, knowledge on TBE in animals is limited; however infections have been reported in dogs [12-15], monkeys [16,17], and horses $[4,18]$. Furthermore seroconversion without specific clinical signs of TBE has been described in some animal species such as cattle and small ruminants $[11,19,20]$. Clinical cases of TBE in ruminants are very seldom; one case of a mouflon (Ovis ammon musimon) for example has been reported from Austria [21]. However, these animals are of significant public health relevance. Especially goats and sheep, more rarely cattle, 
are of importance for the so-called alimentary TBE. During viraemia, the virus is excreted in milk and can be ingested orally by consumption of non-pasteurized milk or cheese produced from raw milk [22-25]. TBE in humans caused by virus-infected milk has occurred in many countries, in the last ten years in Hungary, Austria and Estonia [26-28].

These grazing animals have been shown to be suitable sentinels for the detection of antibodies against TBEV [11], but some questionable points require further examination: (i) the possibility of cross-reactivity of the tested sera with related flaviviruses and (ii) the longevity of TBEV antibody titres in grazing animals.

One example of known cross-reactivity between members of the flavivirus genus comes from serological West Nile virus (WNV) diagnostics [29]. WNV is considered to be the most widespread flavivirus in the world and is transmitted and maintained in an enzootic mosquitobird cycle $[30,31]$. Horses can be infected by bridge vectors and develop subclinical infection or neurological disease. False WNV positive ELISA results from horses have been attributed to cross-reactivity with TBEV specific antibodies and complicate monitoring studies on the WNV sero-prevalence [32].

Here we present results on cross-reactivity within the TBEV-specific serology, but also provide a strategy to identify TBEV antibodies as the cause of false positive reactions in serological tests for other flaviviruses using WNV as an example.

\section{Methods}

\section{Collection of samples}

\section{Sera positive for Flavivirus specific antibodies}

To determine cross-reactivity, five Louping ill virus (LIV) antibody-positive reference sera from sheep (kindly provided by Kim Willoughby, Moredun-Institute, UK) as well as WNV-positive sera from the National Reference Laboratory for WNV (Friedrich-Loeffler-Institut, GreifswaldInsel Riems, Germany) were tested. The WNV sample panel included 15 equine sera (field sera or sera collected after vaccination), and 10 hyperimmune-sera from vaccinated ducks, chickens and rabbits. Additionally, two rabbit sera with antibodies against Usutu virus (USUV) and Japanese encephalitis virus (JEV), respectively, were analyzed.

Furthermore, ascites liquid from mice immunized against TBEV-related viruses such as Russian-spring-summerencephalitis virus (RSSEV), Powassan virus (POWV), Yellow fever virus (YFV), JEV and St. Louis encephalitis virus (SLEV) could be investigated (kindly provided by Gerhard Dobler, Bundeswehr Institute of Microbiology, Munich, Germany). Each sample was diluted 1:10, 1:50, 1:100, 1:500, and 1:1000 before testing (Table 1).
Field sera from horses were collected in two different herds in Bavaria, and sera from TBEV-positive horses [4] were also included (Table 2).

\section{Sera collected to analyze the longevity of the humoral immune response}

Two goats and two sheep were immunized four times as described by Klaus et al. [33] and TBEV antibody titres were traced over a period of 28 months (Table 3 ).

In addition, different field sera were included in the analysis: sera from sheep and goat flocks from the TBE risk areas "Ortenaukreis", "Bodenseekreis" and "BreisgauHochschwarzwald (HS)", and sera from the TBE non-risk area "Altenburger Land" which were collected in 2010 and 2011 (Table 4). Although the sera did not come from the same individual animals, the datasets were compared to the sero-prevalence results exhibited by the same flocks in 2006 and 2009 [11].

In addition, in Salem, district Bodenseekreis, not only sera but also ticks were collected in 2011 (89 female, 116 male, 1537 nymphs, 46 larvae) in the vicinity of the monkey mountain, where in 2006 TBEV strain Salem had first been isolated from a monkey (Macaca sylvanus) $[16,17]$ and sheep sera had been collected and examined in 2008/2009 [34], but TBEV-RNA in ticks has not been detected so far. Ticks were pooled (up to 5 female, 5 male, 10 nymphs, 20 larvae), examined for TBEV-RNA and positive pools were sequenced as described [4].

\section{Test systems}

\section{TBEV specific serology}

All sera were examined by means of a two-step method $[33,34]$, which consisted of (I) first screening with a modified TBEV-antibody ELISA (Immunozym FSME IgM kit, Progen GmbH, Heidelberg, Germany) allowing analysis of the whole immunoglobulin fraction and (II) subsequent confirmation of all ELISA-positive or questionable results by a virus neutralization test (VNT; [10]). Only sera confirmed by VNT were finally classified as TBEV antibody positive.

\section{WNV specific serology}

For detection of WNV-specific antibodies, horse samples were investigated by a commercially available competition ELISA, which allows the species-independent recognition of WNV antibodies against the PrM- and E envelope protein (ID Screen ${ }^{\circ}$ West Nile Competition, IDVet, Grabels, France). Additionally, all serum samples were tested for neutralizing WNV antibodies by VNT with the WNV strain NY 99 (lineage 1, accession no. AF196835) and/or strain Austria (lineage 2, accession no. HM015884, kindly provided by Dr. N. Nowotny, Institute of Virology, University of Veterinary Medicine, Vienna) as described previously [35]. 
Table 1 Cross-reactivities of TBEV-ELISA and TBEV-VNT results

\begin{tabular}{|c|c|c|c|c|}
\hline Sample number & Animal & Antibodies classified as $\left(\mathrm{ND}_{50}\right)$ & TBEV-ELISA & TBEV-VNT $\left(\mathrm{ND}_{50}\right)$ \\
\hline Serum 1 & Sheep & Louping ill-positive & Positive & Positive $(1: 20)$ \\
\hline Serum 2 & Sheep & Louping ill-positive & Negative & Negative (1:5) \\
\hline Serum 3 & Sheep & Louping ill-positive & Positive & Positive (>1:40) \\
\hline Serum 4 & Sheep & Louping ill-positive & Positive & Positive (>1:40) \\
\hline Serum 5 & Sheep & Louping ill-positive & Positive & Positive (>1:40) \\
\hline Serum 6 & Horse & WNV positive (1:320) & Negative & Negative $(<1: 10)$ \\
\hline Serum 7 & Horse & WNV positive (1:480) & Negative & Negative $(<1: 10)$ \\
\hline Serum 8 & Horse & WNV positive (1:1280) & Borderline & Positive $(1: 40)$ \\
\hline Serum 9 & Horse & WNV positive (1:160) & Negative & Negative $(<1: 10)$ \\
\hline Serum 10 & Horse & WNV positive (1:240) & Negative & Negative $(<1: 10)$ \\
\hline Serum 11 & Horse & WNV positive (1:60) & Borderline & Positive (1:80) \\
\hline Serum 12 & Horse & WNV positive $(1: 40)$ & Negative & Negative $(<1: 10)$ \\
\hline Serum 13 & Horse & WNV positive $(1: 80)$ & Negative & Negative $(<1: 10)$ \\
\hline Serum 14 & Horse & WNV positive (1:35) & Negative & Negative $(<1: 10)$ \\
\hline Serum 15 & Horse & WNV positive (1:120) & Negative & Negative $(<1: 10)$ \\
\hline Serum 16 & Horse & WNV positive $(1: 60)$ & Negative & Negative $(<1: 10)$ \\
\hline Serum 17 & Horse & WNV positive (1:80) & Negative & Negative $(<1: 10)$ \\
\hline Serum 18 & Horse & WNV positive $(1: 240)$ & Negative & Negative $(<1: 10)$ \\
\hline Serum 19 & Horse & WNV positive (1:20) & Negative & Negative $(<1: 10)$ \\
\hline Serum 20 & Horse & WNV positive $(1: 40)$ & Negative & Negative $(<1: 10)$ \\
\hline Serum 21 & Horse & WNV positive (1:60) & Negative & Negative $(<1: 10)$ \\
\hline Serum 22 & Horse & WNV positive $(1: 1280)$ & Negative & Negative $(<1: 10)$ \\
\hline Serum 23 & Chicken & WNV positive (1:500) & Negative & Negative $(<1: 10)$ \\
\hline Serum 24 & Chicken & WNV positive $(1: 250)$ & Negative & Negative $(<1: 10)$ \\
\hline Serum 25 & Chicken & WNV positive $(1: 80)$ & Negative & Negative $(<1: 10)$ \\
\hline Serum 26 & Chicken & WNV positive (1:900) & Negative & Negative $(<1: 10)$ \\
\hline Serum 27 & Duck & WNV positive (1:80) & Negative & Negative $(<1: 10)$ \\
\hline Serum 28 & Duck & WNV positive (1:60) & Negative & Negative $(<1: 10)$ \\
\hline Serum 29 & Rabbit & WNV positive (1:120) & Negative & Negative $(<1: 10)$ \\
\hline Serum 30 & Rabbit & WNV positive (1:480) & Negative & Negative $(<1: 10)$ \\
\hline Serum 31 & Rabbit & WNV positive $(1: 80)$ & Negative & Negative $(<1: 10)$ \\
\hline Serum 32 & Rabbit & WNV positive (1:60) & Negative & Negative $(<1: 10)$ \\
\hline Serum 33 & Rabbit & JEV positive (1:60) & Negative & Negative $(<1: 10)$ \\
\hline Serum 34 & Rabbit & JEV positive $(1: 80)$ & Negative & Negative $(<1: 10)$ \\
\hline Serum 35 & Rabbit & USUV positive (1:1280) & Negative & Negative $(<1: 10)$ \\
\hline Serum 36 & Rabbit & USUV positive $(1: 80)$ & Negative & Negative $(<1: 10)$ \\
\hline Ascites 1 & Mouse & RSSEV-positive & Positive* & Positive (1:75) \\
\hline Ascites 2 & Mouse & PoWV-positive & Negative* & Negative $(<1: 25)$ \\
\hline Ascites 3 & Mouse & YFV-positive & Negative* & Negative $(<1: 25)$ \\
\hline Ascites 4 & Mouse & JEV positive & Negative* & Negative $(<1: 25)$ \\
\hline Ascites 5 & Mouse & SLEV positive & Negative* & Negative $(<1: 25)$ \\
\hline
\end{tabular}

*all samples diluted 1:10, 1:50, 1:100, 1:500, 1:1000, only results 1:10 are shown in the table, all samples diluted between 1:50 and 1:1000 were negative. 
Table 2 Cross-reactivity of horse sera between ELISA and VNT

\begin{tabular}{|c|c|c|c|c|c|c|}
\hline \multirow[b]{2}{*}{ Sample } & \multicolumn{2}{|c|}{ TBEV-ELISA } & \multirow{2}{*}{$\begin{array}{c}\text { TBEV-VNT } \\
\mathrm{ND}_{50}\end{array}$} & \multicolumn{2}{|c|}{ WNV-ELISA } & \multirow{2}{*}{$\frac{\text { WNV-VN }}{N D_{50}}$} \\
\hline & $\mathrm{U} / \mathrm{I} 1$ & Result & & $\mathrm{S} / \mathrm{N} \%$ & Result & \\
\hline Serum 1 & $-2,995$ & Negative & n.d. & $92,25 \%$ & Negative & $<1: 10$ \\
\hline Serum 2 & 12,500 & Borderline & $>1: 640 / 1: 960$ & $11,99 \%$ & Positive & $<1: 10$ \\
\hline Serum 3 & $-2,938$ & Negative & n.d. & $88,04 \%$ & Negative & $<1: 10$ \\
\hline Serum 4 & $-3,802$ & Negative & n.d. & $94,11 \%$ & Negative & $<1: 10$ \\
\hline Serum 5 & 3,859 & Negative & n.d. & $41,48 \%$ & Borderline & $<1: 10$ \\
\hline Serum 6 & 17,627 & Positive & $1: 80$ & $7,27 \%$ & Positive & $<1: 10$ \\
\hline Serum 7 & $-2,650$ & Negative & n.d. & $77,31 \%$ & Negative & $<1: 10$ \\
\hline Serum 8 & $-3,571$ & Negative & n.d. & $86,93 \%$ & Negative & $<1: 10$ \\
\hline Serum 9 & $-3,168$ & Negative & n.d. & $90,48 \%$ & Negative & $<1: 10$ \\
\hline Serum 10 & 3,111 & Negative & n.d. & $3,16 \%$ & Negative & $<1: 10$ \\
\hline Serum 11 & $-0,806$ & Negative & n.d. & $93,43 \%$ & Negative & $<1: 10$ \\
\hline Serum 12 & $-3,975$ & Negative & n.d. & $93,54 \%$ & Negative & $<1: 10$ \\
\hline Serum 13 & $-2,995$ & Negative & n.d. & $92,59 \%$ & Negative & $<1: 10$ \\
\hline Serum 14 & $-3,744$ & Negative & n.d. & $89,52 \%$ & Negative & $<1: 10$ \\
\hline Serum 15 & $-2,995$ & Negative & n.d. & $88,38 \%$ & Negative & $<1: 10$ \\
\hline Serum 16 & 4,896 & Negative & n.d. & $86,58 \%$ & Negative & $<1: 10$ \\
\hline Serum 17 & $-3,168$ & Negative & n.d. & $85,80 \%$ & Negative & $<1: 10$ \\
\hline Serum 18 & $-2,765$ & Negative & n.d. & $91,29 \%$ & Negative & $<1: 10$ \\
\hline Serum 19 & 17,915 & Positive & $1: 80$ & $15,04 \%$ & Positive & $<1: 10$ \\
\hline Serum 20 & 20,392 & Positive & $1: 240$ & $51,14 \%$ & Negative & $<1: 10$ \\
\hline Serum 21 & 12,212 & Borderline & $1: 160$ & $13,51 \%$ & Positive & $<1: 10$ \\
\hline Serum 22 & 17,569 & Positive & $1: 320$ & $9,48 \%$ & Positive & $<1: 10$ \\
\hline Serum 23 & $-3,053$ & Negative & n.d. & $84,21 \%$ & Negative & $<1: 10$ \\
\hline Serum 24 & $-3,399$ & Negative & n.d. & $83,57 \%$ & Negative & $<1: 10$ \\
\hline Serum 25 & 16,993 & Positive & $1: 80$ & $7,06 \%$ & Positive & $<1: 10$ \\
\hline Serum 26 & $-4,818$ & Negative & n.d. & $89,77 \%$ & Negative & $<1: 10$ \\
\hline Serum 27 & $-5,867$ & Negative & n.d. & $83,66 \%$ & Negative & $<1: 10$ \\
\hline Serum 28 & $-3,959$ & Negative & n.d. & $84,43 \%$ & Negative & $<1: 10$ \\
\hline Serum 29 & $-5,295$ & Negative & n.d. & $91,08 \%$ & Negative & $<1: 10$ \\
\hline Serum 30 & 10,351 & Borderline & $<1: 5$ & $86,85 \%$ & Negative & $<1: 10$ \\
\hline Serum 31 & $-5,200$ & Negative & n.d. & $86,23 \%$ & Negative & $<1: 10$ \\
\hline Serum 32 & $-4,532$ & Negative & n.d. & $86,37 \%$ & Negative & $<1: 10$ \\
\hline Serum 33 & 31,245 & Positive & $>1: 40 / 1: 720$ & $27,45 \%$ & Positive & $<1: 10$ \\
\hline Serum 34 & 14,168 & Positive & $>1: 40 / 1: 480$ & $76,10 \%$ & Negative & $<1: 10$ \\
\hline Serum 35 & 21,991 & Positive & $1: 40$ & $40,69 \%$ & Borderline & $<1: 10$ \\
\hline Serum 36 & 35,443 & Positive & $>1: 40 />1: 960$ & $21,43 \%$ & Positive & $<1: 10$ \\
\hline Serum 37 & $-5,581$ & Negative & n.d. & $86,84 \%$ & Negative & $<1: 10$ \\
\hline Serum 38 & $-4,913$ & Negative & $<1: 5$ & $88,36 \%$ & Negative & $<1: 10$ \\
\hline Serum 39 & 35,538 & Positive & $>1: 40 / 1: 480$ & $6,68 \%$ & Positive & $<1: 10$ \\
\hline Serum 40 & 30,291 & Positive & $>1: 40 / 1: 960$ & $17,62 \%$ & Positive & $<1: 10$ \\
\hline Serum 41 & $-5,200$ & Negative & $<1: 5$ & $85,33 \%$ & Negative & $<1: 10$ \\
\hline Serum 42 & $-3,864$ & Negative & n.d. & $86,76 \%$ & Negative & $<1: 10$ \\
\hline Serum 43 & $-5,486$ & Negative & n.d. & $87,18 \%$ & Negative & $<1: 10$ \\
\hline
\end{tabular}


Table 2 Cross-reactivity of horse sera between ELISA and VNT (Continued)

\begin{tabular}{|c|c|c|c|c|c|c|}
\hline Serum 44 & $-3,959$ & Negative & n.d. & $87,91 \%$ & Negative & $<1: 10$ \\
\hline Serum 45 & $-5,200$ & Negative & n.d. & $86,37 \%$ & Negative & $<1: 10$ \\
\hline Serum 46 & 13,691 & Positive & $>1: 40 />1: 960$ & $3,07 \%$ & Positive & $<1: 10$ \\
\hline
\end{tabular}

In bold = TBEV-positive horses would result in false positive outcomes in the commercial WNV-ELISA, but clearly negative in the WNV-specific VNT. n.d. = not done.

\section{Results}

\section{Cross-reactivity in TBEV-serology}

The majority of samples from the tested Flavivirusantibody-positive-panel (Table 1) showed clearly negative results using the TBEV-ELISA. Sera with specific antibodies to non-TBEV flaviviruses, such as WNV, JEV, USUV, YFV, SLEV or POWV, scored also clearly negative using the TBEV-ELISA. Nevertheless, four out of five LIV-antibodypositive sheep sera reacted positive in the TBEV-ELISA as well as in the TBEV-VNT. In addition, RSSEV reactive mouse ascites scored also positive in both, the TBEVELISA and the TBEV-VNT, but only at the lowest dilution of 1:10 (Table 1).

\section{Cross-reactivity in WNV serology}

The fifteen WNV-positive horse sera were classified as clearly negative in the TBEV-ELISA, which was confirmed by the TBEV-VNT. Furthermore, $10 \mathrm{WNV}$-specific hyperimmune sera from vaccinated chickens, ducks and rabbits were clearly negative both in the TBEV-ELISA and the TBEV-VNT. The same could be shown for the two hyperimmune sera from JEV and USUV vaccinated rabbits, respectively (Table 1). Therefore, WNV-specific antibodies did not obviously cross- react with our TBEV-specific serology testing.

In contrast, WNV-negative (verified by WNV-specific VNT) horse sera scored positive in the commercial WNV-ELISA. Here it could be verified that TBEV-specific antibodies (ELISA and VNT) were the source of crossreactivity. These results therefore indicate that TBEVspecific antibodies did interfere with WNV-specific ELISA diagnostics and have to be taken into account (Table 2).

Table 3 Longevity of TBEV-antibody titres (VNT) in two immunized goats and sheep

\begin{tabular}{ccccc}
\hline Month* & Goat 1** & Goat 2** & Sheep 1** & Sheep 2** \\
\hline 0 & $<1: 5$ & $<1: 5$ & $<1: 5$ & $<1: 5$ \\
6 & $1: 60$ & $1: 80$ & $1: 80$ & $1: 80$ \\
12 & $1: 80$ & $1: 120$ & $1: 80$ & $1: 80$ \\
18 & $1: 60$ & $1: 320$ & $1: 10$ & $1: 20$ \\
24 & $1: 30$ & $1: 120$ & $1: 30$ & $1: 20$ \\
28 & $1: 80$ & $1: 80$ & $1: 30$ & $1: 60$ \\
\hline
\end{tabular}

*sera examined every month, only selected data shown.

**immunized in week 0, 1, 3 and 11 with one dose of FSME-IMMUN Erwachsene (Baxter Deutschland GmbH, Germany), as described in [33].

$<1: 5=$ negative.
Longevity of TBEV-specific antibody titres in immunized animals and re-testing of sentinel flocks for long-term observations

The development of TBEV-specific antibody titres over a time span of more than two years is shown in Table 3. TBEV-specific antibody titres increased in the vaccinated sheep and goats until 18 weeks after the first immunization and started to decrease to lower VNT titres over the following weeks to reach lower but still positive titres 28 months after vaccination (Table 3 ).

In order to track the development of TBEV-antibodies in the field situation, selected flocks in Baden-Wuerttemberg and Thuringia (Table 4) were repeatedly tested within a time interval of one to four years. Interestingly, the initial results reported for the districts "Bodenseekreis", "Breisgau-HS", and "Ortenaukreis" (Baden-Wuerttemberg), were confirmed [11]. For example, in the sheep flock in Salem (district "Bodenseekreis") a TBEV-sero-prevalence of $13 \%$ was detected (in 2008/2009: 9\%), in the goat flock in "Sulzburg" (district "Breisgau-HS") 17.8\% were seen (2006-09: 43\%), and in a goat flock in "Nordrach" (district "Ortenaukreis") 42.8\% scored positive (2008: 60\%). These findings are in good agreement with the TBE-risk-area status as determined by the Robert Koch-Institute [36,37].

All animal experiments in this study were conducted in strict accordance with a high standard of veterinary care. The protocols were approved by the competent authority of the Federal State of Thuringia, Thuringian State Office for Food Safety and Consumer Protection, Dept. of Health Protection, Veterinary Medicine and Pharmacy, Bad Langensalza, Thuringia, Germany (Reg. no. 04-104/10) and reviewed and approved by the competent authority of the Federal State of MecklenburgWestern Pomerania, State Office for Agriculture, Food Safety and Fisheries, Rostock, Mecklenburg-Western Pomerania, Germany (LALLF M-V/TSD/7221.3-2.5.1002/11).

In addition to these serological results in Salem (Bodenseekreis) 1788 collected ticks in 208 pools were analyzed by TBEV-specific RT-qPCR and in one pool of 10 nymphs collected around the monkey mountain TBEVRNA was detected. The nucleotide sequence (2866 nt in total) of the structure protein genes of TBEV were determined (GenBank KC292217) and compared with the TBEV sequences available in the NCBI GenBank database using BLAST. The highest homology with $99.55 \%$ 
Table 4 Re-tested goat flocks for TBEV-specific antibodies (Thuringia-TH, Baden-Wuerttemberg-BW) and sheep flocks (Baden-Wuerttemberg-BW), re-collected in 2010/11

\begin{tabular}{|c|c|c|c|c|c|c|c|}
\hline Country & District & Flock (village) & Year & Species & No. of sera & No. of positive sera & Seroprev. (\%) \\
\hline BW & Bodenseekreis & S1 (Salem) & 2011 & sheep & 100 & 13 & 13 \\
\hline BW & Bodenseekreis & S1 (Salem) & 2008-09* & sheep & 100 & 9 & 9 \\
\hline BW & Breisgau (HS) & Sulzburg & 2010 & goats & 28 & 5 & 17,8 \\
\hline BW & Breisgau (HS) & Sulzburg & $2006-09^{*}$ & goats & 28 & 12 & 43 \\
\hline BW & Breisgau (HS) & different flocks** & 2010 & goats & 355 & 4 & 1,1 \\
\hline BW & Breisgau (HS) & different flocks** & $2006-09^{*}$ & goats & 349 & 13 & 3,7 \\
\hline BW & Ortenaukreis & Nordrach & 2010 & goats & 28 & 12 & 42,8 \\
\hline BW & Ortenaukreis & Nordrach & $2008^{*}$ & goats & 20 & 12 & 60 \\
\hline BW & Ortenaukreis & various flocks*** & 2010 & goats & 100 & 15 & 15 \\
\hline BW & Ortenaukreis & various flocks & $2008^{*}$ & goats & 355 & 51 & 14,4 \\
\hline $\mathrm{TH}$ & Altenburger Land & A1 (Altkirchen) & 2011 & goats & 90 & 0 & 0 \\
\hline $\mathrm{TH}$ & Altenburger Land & A1 (Altkirchen) & $2009^{*}$ & goats & 73 & 5 & 7 \\
\hline
\end{tabular}

*in detail published in [11].

${ }^{* *}$ re-tested flocks from Horben, Münstertal and Löffingen-Dittishausen, results not shown in detail.

***flocks from Haslach, Kürzell-Meißenheim, Offenburg, Hohberg, results not shown in detail.

was ascertained for TBEV strain Salem (GenBank FJ5 72210). Here 2853 nt of the compared 2866 nt were identical.

Interestingly, the results from a flock in Thuringia surveyed in 2009 could not be confirmed: In 2009, surprisingly five out of 73 sera in this goat flock in "Altkirchen" in the district "Altenburger Land", Thuringia, which is defined as a TBE non-risk area, tested TBEV-antibody-positive
[11]. In 2011, we tested 90 sera from this flock and did not find any TBEV-antibody-positive sera (Table 4). The map (Figure 1) shows the four districts where sera were collected.

\section{Discussion}

A limited cross-reactivity of non-TBEV, but flavivirusantibody-positive sera was observed in the TBEV-specific

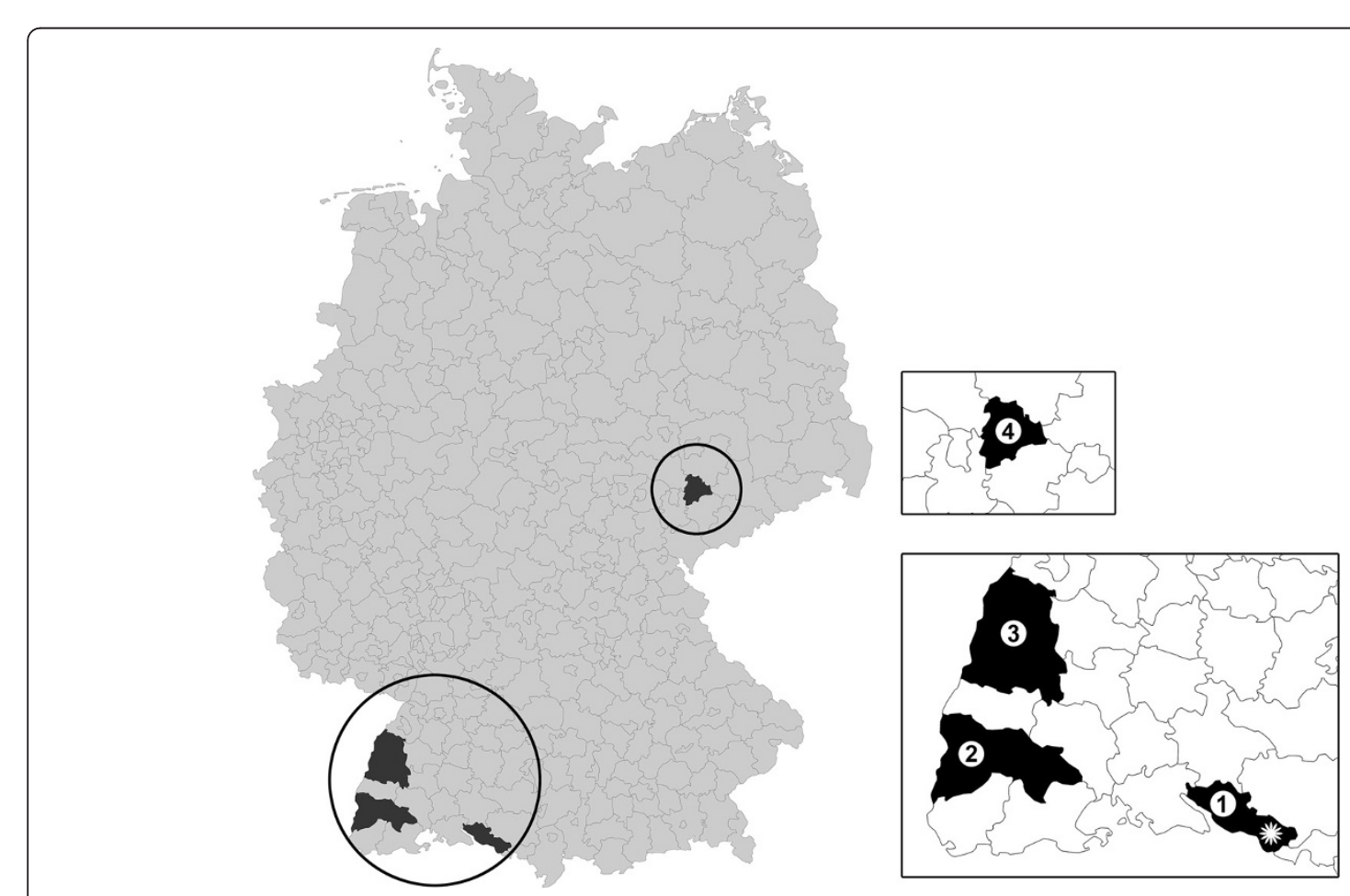

Figure 1 Places of re-tested flocks in Baden-Wuerttemberg and Thuringia. 1: Bodenseekreis; 2: Breisgau-Hochschwarzwald; 3: Ortenaukreis; 4: Altenburger Land; star: in addition tick collection site. 
test strategy (ELISA and VNT) used for the selection of regions with a risk for TBEV infection. Four of five sera defined as LIV-antibody positive and ascites from a RSSEVinfected mouse reacted positive in the ELISA as well as in the VNT assay (Table 1). Therefore, TBEV-serology in most cases is not able to differentiate between LIVantibody-positive, RSSEV-antibody-positive and TBEVantibody-positive sera, and an intense cross-reactivity of sera specific for these related viruses must be assumed. Phylogenetic analysis of the genus Flavivirus confirmed the close relationship of LIV, RSSEV and TBEV [38]. However, since to our knowledge human TBE cases have not been described in Great Britain [1,39], it must be concluded that double infection with Louping ill and TBEV as a reason for these results can be excluded. Cross-reactivity would only be relevant in countries where both diseases are present. In Germany, Louping ill as well as RSSE has not been observed to date [39]. In addition, clinical signs of Louping ill in sheep are severe, while TBE infection in ruminants normally is subclinical [39-41].

Furthermore, no cross-reactivity was observed between our TBEV test system (ELISA and VNT) and defined WNV-positive horse sera (Table 1).

It is well-known, that the used commercial competitive WNV-ELISA cross-reacts with other flaviviruses [29,32], necessitating the use of virus-specific neutralization assays for the final determination of the etiologic flavivirus. Here, the cumulative occurrence of false-positive WNVresults with the used commercial WNV-ELISA system (Table 2) is the consequence of a clear cross-reactivity with TBEV-specific antibodies. In this case, a reasonable discrimination is only possible by means of a virus-specific neutralization assay. The results of this study are therefore in good agreement with those of a previous study [29]. In Germany, TBEV-related diseases in horses have been reported recently [4,42]. Müller et al. [42] investigated a population of 240 horses in the endemic region of Marburg-Biedenkopf and identified 2.9\% horses with TBEV-neutralizing antibodies. Consequently, TBEV should be considered as an important and relevant differential diagnosis for WNV infections in horses, although there is no evidence for indigenous WNV infections in Germany so far [32]. Our results are in accordance with a similar study in Austria, where an unexpectedly high seroconversion rate against TBEV was identified in a large herd of horses [43]. Therefore, our TBEV test system could also be helpful for clarifying non-specific serological WNV antibody-reactive results in regions without a WNV history.

On the other hand, testing of horses can even be used as an indicator to detect TBEV-affected areas and thus identify a TBEV focus.

In summary, our TBEV antibody test system is well suited and, despite a partial cross-reactivity to LIV- and
RSSEV-antibodies, cross-reactivity with other flaviviruses is not to be expected in countries like Germany. However, the number of samples tested so far has been low, so these findings should be verified in future studies.

In our investigations on the longevity of TBEV antibody titres, only small differences were seen between the two immunized goats and sheep. TBEV-specific antibody titres were still detectable after 28 months with lower but specific titres in the two goats and two sheep (Table 3). While the progress of TBEV antibody titres reflects the situation after immunization with an inactivated vaccine, natural infection might result in relatively similar humoral immune responses; e.g. in horses it was possible to re-test naturally infected TBEV-antibody-positive animals. In two flocks in Bavaria, all six TBEV antibody-positive horses which were re-tested after nine months had VNT-positive titres and it was also possible to detect TBEV in ticks collected in the vicinity of the stables [4]. Also Leschnik et al. [14] observed TBEV titres in dog sera for nine months after natural infection.

In addition, in repeatedly tested goat and sheep flocks the detected sero-prevalences were in good accordance with the epidemiological TBEV situation in the surroundings. In the district "Bodenseekreis", a defined TBE risk area with a very long TBEV history, 60 human cases were registered between 2001 and 2012, and the existence of a TBEV natural focus in Salem described in animals in 2006 $[16,17,34]$ was re-confirmed by TBEV antibody-positive sheep sera (Table 4). Detection of TBEV-RNA (GenBank KC292217) closely related to the TBEV strain "Salem" (GenBank FJ572210) in one pool of 10 nymphs among 1788 collected ticks also confirmed the serological results (data not shown in detail). This strain was first isolated and sequenced from a monkey (Macaca sylvanus) from the monkey mountain Salem with severe neurological clinical symptoms in 2006 [16,17]. However, until our here presented results TBEV-RNA could not be found in ticks at this place. . After our investigations in horse herds in Bavaria [4] it was an additional case where sera from grazing animals as sentinels were successfully used for a targeted tick collection to detect TBEV-RNA.

The districts "Breisgau-HS" and "Ortenaukreis" also have a well-known TBEV history with 64 (Breisgau-HS) and 246 (Ortenaukreis) human cases, respectively, between 2001 and 2012.

In the goat flock in "Altkirchen", district "Altenburger Land" (Thuringia), however, re-testing provided a different unexpected result. Surprisingly, in 2009, five of 73 sera from this TBE non-risk area with so far no human TBE cases had been found to be TBEV antibody-positive (7\%). In 2011, 90 sera from new goats of this flock were re-tested and no TBEV antibody-positive results were detected (Table 4). One reasonable explanation might be the elimination of the relevant animals from the flock, 
since persistence of TBEV-specific antibody titres is possible for more than 28 months.

Therefore, detection of a small number of TBEV antibody-positive sera in TBEV non-risk areas with no human TBE cases should be interpreted with care (animals might originate from TBE risk areas). However, the longevity data support the conclusion that sera from grazing animals are well suited as a valuable source of serological data supporting the TBEV status of an area.

\section{Conclusions}

TBEV-specific sero-prevalences in animals are an additional valuable tool that can help identify natural TBEV foci which are in most cases spread in a patchwork-like pattern. Cross-reactivity is rare and does not play a significant role in countries without a prevalence of a broad range of TBEV-related flaviviruses. Furthermore, TBEV is a very important and relevant cause for false-positive WNV-ELISA results in horses and must be taken into consideration in monitoring or sentinel programs.

Finally, all TBEV serology results should be interpreted in close cooperation between human and veterinary medicine, and recommendations for the vaccination of humans, based exclusively on the TBEV sero-prevalence in animals should be avoided.

\section{Competing interests}

The authors declare that they have no competing interests nor did they have any competing financial interests in relation to the work described.

\section{Authors' contributions}

CK collected sera from immunized animals, carried out ELISA, evaluated and interpreted data of TBEV, wrote the manuscript; UZ evaluated and interpreted data of WNV, wrote this part of manuscript; DK developed and carried out VNT; BH developed and carried out RT-qPCR; MB designed the study and drafted the manuscript. All authors revised the manuscript critically and approved the final version.

\section{Acknowledgements}

The authors are very grateful to Elisabeth Hasse, Doreen Reichelt, Mareen Lange, Christian Korthase and Cornelia Steffen for excellent technical assistance. They would also like to thank Udo Moog and Ute Schau (Thüringer Tierseuchenkasse, Tiergesundheitsdienst, Jena, Germany) for sera collected in Thuringia, Wolf Bader (Schafherdengesundheitsdienst Baden-Wuerttemberg, Aulendorf, Germany) and Regine Saier (Institute of Food Science and Biotechnology, University of Hohenheim, Stuttgart, Germany) for sera collected in Baden-Wuerttemberg, Kim Willoughby (Moredun-institute, GB) for Louping ill-antibody positive sera, and Gerhard Dobler (Bundeswehr Institute of Microbiology, Munich, Germany) for samples from mice. We wish to thank Wolfram Maginot (Friedrich-Loeffler-Institut, Jena, Germany) for constructing the figure.

\section{Author details}

${ }^{1}$ Institute of Bacterial Infections and Zoonoses, Friedrich-Loeffler-Institut, Naumburger Str. 96a, D-07743 Jena, Germany. ${ }^{2}$ Institute of Novel and Emerging Infectious Diseases, Friedrich-Loeffler-Institut, Südufer 10, D-17493 Greifswald-Insel Riems, Germany. ${ }^{3}$ Institute of Diagnostic Virology, Friedrich-Loeffler-Institut, Südufer 10, D-17493 Greifswald-Insel Riems, Germany.

Received: 25 November 2013 Accepted: 26 March 2014

Published: 1 April 2014

\section{References}

1. Süss J: Tick-borne encephalitis, Epidemiology, risk areas, and virus strains in Europe and Asia - An overview. Ticks Tickborne Dis 2010, 2011(2):2-15.

2. Korenberg E: Recent epidemiology of tick-borne encephalitis: an effect of climate change? Adv Virus Res 2009, 74:123-144.

3. Kupča AM, Essbauer S, Zoeller G, de Mendonça PG, Brey R, Rinder M, Pfister K, Spiegel M, Doerrbecker B, Pfeffer M, Dobler G: Isolation and molecular characterization of a tick-borne encephalitis virus strain from a new tick-borne encephalitis focus with severe cases in Bavaria, Germany. Ticks Tickborne Dis 2010, 1:44-51.

4. Klaus $C$, Hörügel U, Hoffmann B, Beer M: Tick-borne encephalitis virus (TBEV) infection in horses: Clinical and laboratory findings and epidemiological investigations. Vet Microbiol 2013, 163:368-372.

5. Oehme R, Hartelt K, Backe H, Brockmann S, Kimmig P: Foci of tick-borne diseases in Southwest Germany. Int J Med Microbiol 2002, 291(Suppl 33):22-29.

6. Süss J, Schrader C, Falk U, Wohanka N: Tick-borne encephalitis (TBE) in Germany - epidemiological data, development of risk areas and virus prevalence in field-collected ticks and in ticks removed from humans. Int J Med Microbiol 2004, 293(Suppl 37):69-79.

7. Gäumann R, Mühlemann K, Strasser M, Beuret CM: High-throughput procedure for tick surveys of tick-borne encephalitis virus and its application in a national surveillance study in Switzerland. Appl Environ Microbiol 2010, 76:4241-4249.

8. Klaus C, Hoffmann B, Hering U, Mielke B, Sachse K, Beer M, Süss J: Tick-borne encephalitis (TBE) virus prevalence and virus genome characterization in field-collected ticks (Ixodes ricinus) in risk, non-risk, and former risk areas of TBE and in ticks removed from humans in Germany. Clin Microbiol Infect 2010, 16:238-244.

9. Achazi K, Růžek D, Donoso-Mantke D, Schlegel M, Ali HS, Wenk M, Schmidt-Chanasit J, Ohlmeyer L, Rühe F, Vor T, Kiffner T, Kallies R, Ulrich RG, Niedrig M: Rodents as sentinels for the prevalence of tick-borne encephalitis virus. Vector Borne Zoonotic Dis 2011, 11:641-647.

10. Klaus C, Hoffmann B, Moog U, Schau U, Beer M, Süss J: Can goats be used as sentinels for tick-borne encephalitis (TBE) in non-endemic areas? Experimental studies and epizootiological observations. Berl Munch Tierarztl Wochenschr 2010, 123:441-445.

11. Klaus C, Beer M, Saier R, Schau U, Moog U, Hoffmann B, Diller R, Süss J: Goats and sheep as sentinels for tick-borne encephalitis (TBE) virus epidemiological studies in areas endemic and non-endemic for TBE virus in Germany. Ticks Tickborne Dis 2012, 3:27-37.

12. Tipold A, Fatzer R, Holzmann H: Zentraleuropäische Zeckenenzephalitis beim Hund. [Central-European tick-borne encephalitis in dogs]. Kleintierpraxis 1993, 38:619-628. in German, with English abstract.

13. Weissenböck H, Suchy A, Holzmann H: Tick-borne encephalitis in dogs: neuropathological findings and distribution of antigen. Acta Neuropathol 1998, 95:361-366.

14. Leschnik MW, Kirtz GC, Thalhammer JG: Tick-borne encephalitis (TBE) in dogs. Int J Med Microbiol 2002, 291(Suppl 33):66-69.

15. Kirtz G, Kölbl S, Czettel B, Thalhammer JG: Frühsommer-Meningoenzephalitis (FSME, Zentral-europäische Zeckenenzephalitis) beim Hund in Österreich: eine Seroprävalenzstudie. [Tick-borne encephalitis (TBE) in dogs in Austria: a seroprevalence study]. Kleintierpraxis 2003, 48:133-140. in German, with English abstract.

16. Süss J, Gelpi E, Klaus C, Bagon A, Liebler-Tenorio EM, Budka H, Stark B, Müller W, Hotzel H: Tickborne encephalitis in naturally exposed monkey (Macaca sylvanus). Emerg Infect Dis 2007, 13:905-907.

17. Süss J, Dobler G, Zöller G, Essbauer S, Pfeffer M, Klaus C, Liebler-Tenorio EM, Gelpi E, Stark B, Hotzel H: Genetic characterisation of a tick-borne encephalitis virus isolated from the brain of a naturally exposed monkey (Macaca sylvanus). Int J Med Microbiol 2008, 298(Suppl 44):295-300.

18. Waldvogel K, Matile H, Wegmann C, Wyler R, Kunz C: Zeckenenzephalitis beim Pferd [Tick-borne encephalitis in the horse]. Schweiz Arch Tierheilkd 1981, 123:227-233 (in German).

19. Grešíková M, Sekeyová M, Stúpalová S, Necas S: Sheep milk-borne epidemic of tick-borne encephalitis in Slovakia. Intervirology 1975, 5:57-61.

20. Leutloff R, Nübling M, Neumann-Haefelin D, Rieger MA: Cows as indicators for TBE endemic regions: suitability of testing for antibodies in serum and milk. Int J Med Microbiol 2006, 296(Suppl 40):87-88. 
21. Bagó Z, Bauder B, Kolodziejek J, Nowotny N, Weissenböck H: Tickborne encephalitis in a mouflon (Ovis ammon musimon). Vet Rec 2002, 150(7):218-220.

22. Van Tongeren HA: Encephalitis in Austria. IV. Excretion of virus by milk of the experimentally infected goat. Archiv für die Gesamte Virusforschung 1955, 6:158-162.

23. Grešíková M: Recovery of the tick-borne encephalitis virus from the blood and milk of subcutaneously infected sheep. Acta Virol 1958, 2:113-119.

24. Grešíková M: Excretion of the tick-borne encephalitis virus in the milk of subcutaneously infected cows. Acta Virol 1958, 2:188-192.

25. Grešíková M, Rehacek J: Isolation of the tick-borne encephalitis virus from the blood and milk of domestic animals (sheep and cow) after infection by ticks of the family Ixodes ricinus. Archiv für die Gesamte Virusforschung 1959, 9:360-364.

26. Balogh Z, Ferenczi E, Szeles K, Stefanoff P, Gut W, Szomor K, Takacs M, Berencsi G: Tick-borne encephalitis outbreak in Hungary due to consumption of raw goat milk. J Virol Methods 2010, 163:481-485.

27. Holzmann H, Aberle SW, Stiasny K, Werner P, Mischak A, Zainer B, Netzer M, Koppi S, Bechter E, Heinz FX: Tick-borne encephalitis from eating goat cheese in a mountain region of Austria. Emerging Infect Dis 2009, 15:1671-1673.

28. Kerbo N, Donchenko I, Kutsar K, Vasilenko V: Tick-borne encephalitis outbreak in Estonia linked to raw goat milk. Euro Surveill 2005, 10:2-4.

29. Ziegler U, Seidowski D, Angenvoort J, Eiden M, Müller N, Nowotny N, Groschup MH: Monitoring of West Nile virus infections in Germany. Zoonoses Public Health 2012, 59(Suppl 2):95-101.

30. Calistri P, Giovanni A, Hubálek Z, Ionescu A, Monaco F, Savini G, Lelli R: Epidemiology of West Nile in Europe and in the Mediterranean basin. Open Virol J 2010, 4:29-37.

31. Weissenböck H, Hubálek Z, Bakonyi T, Nowotny N: Zoonotic mosquito-borne flaviviruses: Worldwide presence of agents with proven pathogenicity and potential candidates of future emerging diseases. Vet Microbiol 2010, 144:271-280.

32. Ziegler U, Angenvoort J, Klaus C, Nagel-Kohl U, Sauerwald C, Thalheim S, Horner S, Braun B, Kenklies S, Tyczka J, Keller M, Groschup MH: Use of competition ELISA for monitoring of West Nile virus infections in horses in Germany. Int J Environ Res Public Health 2013, 10:3112-3120.

33. Klaus $C$, Beer M, Saier R, Schubert $H$, Bischoff S, Süss J: Evaluation of serological tests for detecting tick-borne encephalitis virus (TBEV) antibodies in animals. Berl Munch Tierarztl Wochenschr 2011, 124:443-449.

34. Klaus C, Hoffmann B, Beer M, Müller W, Stark B, Bader W, Stiasny K, Heinz FX, Süss J: Seroprevalence of tick-borne encephalitis (TBE) in naturally exposed monkeys (Macaca sylvanus) and sheep and prevalence of TBE virus in ticks in a TBE endemic area in Germany. Ticks Tickborne Dis 2010, 1:141-144.

35. Ziegler U, Seidowski D, Globig A, Fereidouni SR, Ulrich RG, Groschup MH: Sentinel birds in wild-bird resting sites as potential indicators for West Nile virus infections in Germany. Arch Virol 2010, 155:965-969.

36. Robert-Koch-Institute: FSME: Risikogebiete in Deutschland. [TBE risk areas in Germany.]. Epid Bull 2007, 15:129-135. in German.

37. Koch-Institute R: FSME: Risikogebiete in Deutschland [TBE risk areas in Germany]. Epid Bull 2013, 22:151-162 (in German).

38. Gould EA, Solomon T: Pathogenic flaviviruses. Lancet 2008, 371:500-509

39. Hubálek Z, Rudolf I: Tick-borne viruses in Europe. Parasitol Res 2012, 111:9-36

40. Gao GF, Jiang WR, Hussain MH, Venugopal K, Gritsun TS, Reid HW, Gould EA: Sequencing and antigenic studies of a Norwegian virus isolated from encephalomyelitic sheep confirm the existence of louping ill virus outside Great Britain and Ireland. J Gen Virol 1993, 74:109-114.

41. Dobler G: Zoonotic tick-borne flaviviruses. Vet Microbiol 2010, 40:221-228.

42. Müller K, König M, Thiel HJ: Die tick-borne Enzephalitis (TBE) unter besonderer Berücksichtigung der Infektion beim Pferd. [Tick-borne encephalitis (TBE) with special emphasis on infection in horses]. Dtsch Tieraerztl Wochenschr 2006, 113:147-151. in German, with English abstract.

43. Rushton JO, Lecollinet S, Hubálek Z, Svobodva P, Lussy H, Nowotny N: Tick- borne encephalitis virus in horses, Austria 2011. Emerg Infect Dis 2013, 19:635-637.

doi:10.1186/1746-6148-10-78

Cite this article as: Klaus et al:: Tick-borne encephalitis virus (TBEV) findings on cross reactivity and longevity of TBEV antibodies in animal sera. BMC Veterinary Research 2014 10:78.

\section{Submit your next manuscript to BioMed Central and take full advantage of:}

- Convenient online submission

- Thorough peer review

- No space constraints or color figure charges

- Immediate publication on acceptance

- Inclusion in PubMed, CAS, Scopus and Google Scholar

- Research which is freely available for redistribution

Submit your manuscript at www.biomedcentral.com/submit
C) BioMed Central 